\title{
Depresio- eta antsietate-sintomen eta hanturaren arteko erlazioa bularreko minbizia gainditutako emakumeetan
}

\author{
Association between anxiety and depressive symptoms and inflammation in \\ breast cancer survivors
}

\author{
Ainitze Labaka ${ }^{1,2}$, Amaia Arregi ${ }^{1}$, Oscar Vegas ${ }^{1}$, Larraitz Garmendia ${ }^{1}$, Joana Camba ${ }^{3}$, \\ Joana Perez-Tejada ${ }^{1,3^{*}}$ \\ ${ }^{1}$ Erizaintza II saila, UPV/EHU \\ ${ }^{2}$ Oinarrizko prozesu psikologikoak eta haien garapena saila, UPV/EHU \\ ${ }^{3}$ Onkologikoa Fundazioa \\ *joana.perez@ehu.eus
}

\section{Laburpena}

Bularreko minbizia gainditutako emakumeen antsietate- eta depresio-prebalentzia biztanleria orokorrarena baino handiagoa da. Nahasmendu horien eta minbiziaren arteko fisiopatologian zenbait faktore berdin aurki daitezke: hantura, zitokinak eta kortisola. Ikerketa honen helburua bularreko minbizia gainditutako emakumeetan depresio- eta antsietate-sintomen eta hanturaadierazleen arteko erlazioa aztertzea da. Kortisol-maila handiagoak aurkitu ditugu antsietate- eta depresio-sintomak dituzten emakumeetan. Gainera, TNF- $\alpha$ maila altuak aurkitu ditugu depresioa duten emakumeetan.

Gako-hitzak: bularreko minbizia, kortisola, depresioa, antsietatea, hantura-zitokinak

\section{Abstract}

The diagnosis of anxiety and depression is higher in breast cancer survivors than in general population. Proinflammatory cytokines and cortisol are involved in both cancer physiopathology and affective disorders physiopathology. Thus, we aim to investigate the relationship between depressive and anxiety symptoms and inflammatory biomarkers in breast cancer survivors. The results showed that women with anxiety disorders had increased cortisol level. In addition, elevated TNF- $\alpha$ levels were found in subjects with depression.

Keywords: breast cancer, cortisol, depression, anxiety, proinflammatory cytokine.

Bidalia: 2019ko ekainaren 14an.

Onartua: 2019ko abenduaren 3an.

http://doi.org/10.26876/osagaiz.2.2019.263

\section{Sarrera eta motibazioa}

Osasun-aurrerakuntzei esker bularreko minbizia diagnostikatutako emakumeen bizi-itxaropena bost urtera \% 85ekoa izatera iritsi da (1). Hori dela eta, osasun esku-hartzeek bizirik irtetetik haratago jarri dute ikusmira, minbizia gainditu duten pertsonen bizi-kalitatea bermatzea ere helburutzat hartuz. 
Emakumezkoei eragiten dieten minbizien herena bularrekoa da, sexu honetan gehien diagnostikatzen den minbizi motaren postua hartuz. 2012. urtetik aurrera \% 30 hazi da kasu berrien kopurua, eta 2018an Espainian 32.825 kasu berri erregistratu ziren (2). Osasun-egoeran ez ezik, maila profesionalean, gorputz-irudian eta harreman sozialetan eta familiartekoetan ere eragin handia du bularreko minbiziak (3-5). Horrelako egoera mehatxagarri baten aurrean egokitzeko ezintasunari eta ondoriozko aktibazio psikofisiologiko desegoki kronikoari distresa deritzo. Distresa estres negatiboa da eta beraz, oso ohikoa da bizi-zikloko trantsizio-faseetan. "National Comprehensive Cancer Network"-en arabera, minbiziaren diagnostikoa eta tratamendua hastearen zein amaitzearen kalteondorio zuzena da distresa (6), eta morbi-mortalitatean eragiten du, baita bizi-kalitatean ere (7). Halaber, depresioa bezalako nahasmenduen agerpena errazten du (8).

Zentzu horretan, bularreko minbizia gainditutako emakumeetan antsietate- eta depresio-sintomen prebalentzia \% 40 ingurukoa dela adierazten dute datuek, biztanleria orokorrean baino 3 bider handiagoa $(9,10)$. Nahasmendu horiek bizi-kalitatea eta osasun-egoera eskasagoak izatea eragiten dute. Hori gutxi balitz, depresioak bizi-itxaropena murriztu eta minbiziaren progresioa eta berragertzea erraz ditzake (11).

Hortaz, minbiziak eta nahaste emozionalek lotura estua dute. Gainera, markatzaile biologiko komunak dituztela ikusi da. Batetik, minbiziari aurre egiteko, organismoak immunitate-sistema aktibatu eta hantura zitokinak jariatzen ditu. Depresioa eta antsietatea duten pazienteetan ere hantura-zitokinaren maila areagotua aurkitu ohi da (12). Bestetik, minbizi-kasuetan nahiz nahasmendu emozionaletan, kortisolak, estresaren hormonak alegia, gora egiten duela ikusi da $(11,13)$.

\section{Arloko egoera eta ikerketaren helburuak}

Psikoneuroimmunologia garunaren, jokabidearen eta immunitate-sistemaren arteko harremana aztertzen duen esparrua da, eta faktore psikosozialek jokabide-mekanismoekin eta mekanismo biologikoek elkarri nola eragiten dioten aztertzen du osasun-gaixotasun orekaren testuinguruan (14). Izan ere, garunak immunitate-prozesua erregulatzen du, eta atzera berriz, immunitate-sistemak funtzio neuronal eta endokrinoak erregula ditzake, jokabideari ere eraginez. Testuinguru horretan, hantura-zitokina deritzen molekula proteiko mezulariek berebiziko garrantzia dute, sistema ezberdinen arteko bitartekari baitira (15).

Diziplina hori oinarritzat hartuz, bularreko minbizia gainditutako emakumeek duten depresioprebalentzia handiagoa ulertzeko gakoa jokabidearen, hantura-zitokinen eta kortisolaren elkarrekintzan egon daiteke:

- Depresioaren hanturaren hipotesiaren arabera, estresak 6 Interleukina (IL-6) eta Tumorearen Nekrosi Faktorea (TNF- $\alpha$ ) jariaraz dezake. Horiek, berriz, kortisol-maila areagotu. Egoera honek luze iraunez gero, estres-erantzuna kontrolatzen duen hipotalamo-pituitaria-adrenal (HPA) ardatza desdoitu egiten da eta ezin ditu kortisol-mailak bere onera ekarri. Gainera, periferian askatutako zitokinek garuneko hesi hematoentzefalikoa zeharka dezakete, garunean hartzaile espezifikoei lotu, anplifikatu eta funtzio neuronala erasan dezakete, jokabideari eta aldarte-egoerari eraginez (15).

- Bularreko minbizia gainditutako emakumeetan kortisol, IL-6 eta TNF- $\alpha$ maila handiak aurkitu dira $(16,17)$.

- Hantura-prozesuak barne hartzen dituzten gaitzetan, depresio-nahasmenduen intzidentzia handiagoa dela ikusi da (8), bularreko minbizia tarteko (10).

Bularreko minbizia gainditu duten emakumeen osasun-egoeraren inguruko ikerketak egin badira ere, lan gutxik aztertu dituzte aldagai fisiologikoak eta psikologikoak batera, eta are gutxiago haien arteko lotura. Hori dela-eta, ikerketa honen helburua hauxe da: bularreko minbizia gainditutako 
emakumeen depresio- eta antsietate-mailak aztertzea, eta horiek hantura-zitokina periferikoekin eta kortisol-mailarekin duten erlazioa ikertzea. Horretarako, honako helburu zehatz hauek landuko dira:

1. Bularreko minbizia gainditutako emakumeen depresio- eta antsietate-maila behatzea.

2. Plasmako TNF- $\alpha$, IL- 6 eta kortisol-mailak neurtzea.

3. Aldagai fisiologikoak depresio- eta antsietate-sintomen arabera konparatzea.

\section{Ikerketaren muina}

Zeharkako ikerketa deskribatzaile hau aurrera eramateko, honako esperimentua gauzatu zen:

\subsection{Parte-hartzaileak}

Onkologikoa Fundazioan tratatutako bularreko minbizia gainditutako 80 emakume boluntario aztertu ziren. Parte hartzeko proposamena inklusio-irizpideak betetzen zituzten emakume guztiei luzatu zitzaien beren osasun-errebisioaren zitan. Inklusio-irizpideak honakoak izan ziren: (a) adina 30-70 urte, (b) minbiziaren tratamendu-fase guztiak bete izana (kirurgia, kimioterapia eta erradioterapia), eta (c) tratamendua amaitu zenetik gehienez bost urte eta gutxienez urtebete igaro izana. Esklusioirizpideak: (a) metastasia izatea, (b) immunitate-sistemari eragiten dioten egoera klinikoak pairatzea (kortikoide-tratamendua jasotzen egotea edota artritisa bezalako gaixotasun immunitario kronikoak pairatzea). Inklusio-irizpidea betetzen zuten emakumeei odol-analisi bat egiteko eta elkarrizketa psikologiko bat egiteko deitu genien. Edozein datu bildu aurretik, baimen informatuak jaso ziren. UPV/EHUko Etika Batzordearen onespena jaso zuen proiektuak. Jarraitutako prozedurak ere legedi nazionala bete zuen.

\subsection{Aldagai psikologiko eta fisiologikoak}

Antsietate- eta depresio-maila "Hospital Anxiety and Depression Scale" (HADS) (18) tresnaren bidez ebaluatu zen. HADS eskala ospitaleratuta egon diren pertsonen distres psikologikoa neurtzeko erabiltzen da. Test hau Likert motako zazpi galderaz osatutako bi azpieskalatan banatzen da: antsietatea eta depresioa. Azpieskala bakoitzaren puntuazioa 0 eta 21 artekoa da, eta paziente onkologikoetan egindako galdetegi-balidazioaren arabera, antsietate-sintoma esanguratsuak daudela esan daiteke antsietatearen azpieskalan 9 puntu edo gehiago izanez gero, eta depresio-sintoma esanguratsuak daudela esan daiteke dagokion eskalan 4 puntutik gora erregistratuz gero (19). Cronbach-en alfa koefizientea 0,840koa eta 0,780koa izan zen azpieskala bakoitzarentzat, hurrenez hurren. Odol-lagina hodietan jaso zuten erizainek (Vacutainer SST II Advance) seruma bereizteko hodiak zentrifugatu eta -80 oC-ra biltegiratu zuten. IL-6 eta TNF- $\alpha$ kontzentrazioak Elisa kit-a (R\&D Systems, EEBB) eta ELx 800 plater-irakurgailua (BioTek, EEBB) erabilita neurtu ziren. IL- 6 eta TNF- $\alpha$ immunosaiakuntzen sentikortasuna 0,039 eta $0,106 \mathrm{pg} / \mathrm{m}$-koa izan zen hurrenez hurren. Kortisolmaila elkarrizketa psikologikoaren bezperan jaso zuten parte-hartzaileek esnatzerakoan, erritmo zirkadianoagatiko aldakortasuna ekiditeko. Horretarako, listua jasotzeko ontzi bat eman zitzaien, argibideak eman, eta 4 ㅇ-ra gorde zuten. Kortisol-kontzentrazioa zitokinena bezalaxe neurtu zen. Haren immunosaiakuntza-sentikortasuna 0,007 $\mu \mathrm{g} / \mathrm{dL}$-koa izan zen. Analisi estatistiko guztiak SPSS 24.0 erabiliz egin ziren. Korrelazioak Pearsonen testaren bidez aztertu ziren. Bariantzaren analisia egiterakoan, hormonoterapia jasotzea, adina, tratamendua amaitu zenetik pasatako denbora eta momentuko tratamendu farmakologikoa aldagaiak kontrolatu ziren. Esangura-irizpidea $p<0,05$-ean finkatu zen.

\subsection{Emaitzak}

Parte-hartzaileen adina 56,3 urtekoa izan zen batez beste, gehiengoak bikote egonkorra zuen $(\% 77,5)$ eta guztiak ere bigarren hezkuntza-maila jasotakoak ziren gutxienez. Emakumeen \% 32,5ek depresio-sintomak agertu zituen eta \% 31,3k antsietate-sintomak HADSaren irizpideen arabera. Ezaugarri demografikoak eta estatistiko deskribatzaileak 1. taulan ageri dira. 
1. taula. Laginaren ezaugarriak.

\begin{tabular}{lr}
\hline Aldagaiak $(\mathrm{n}=80$ ) & \\
\hline Adina (Batezbesteko \pm SD) & $56,3 \pm 8,57$ \\
Tratamendua amaitu ondorengo denbora & $22,4 \pm 13,3$ \\
(hilabetetan, batezbesteko \pm SD) & \\
Ezkontza-estatusa & 6,25 \\
$\quad$ Ezkongabea (\%) & 77,5 \\
Ezkondua (\%) & 12,5 \\
Dibortziatua (\%) & 3,75 \\
Alarguna (\%) & \\
Heziketa-maila & 70 \\
$\quad$ Bigarren hezkuntza (\%) & 30 \\
Hirugarren hezkuntza edo gehiago (\%) & 32,5 \\
Depresio-sintomak (\%) & 31,3 \\
Antsietate-sintomak (\%) & \\
\hline
\end{tabular}

Korrelazio positiboa aurkitu zen kortisolaren eta HADSaren irizpideen araberako antsietate- eta depresio-sintomatologiaren artean. IL-6aren eta antsietatearen artean korrelazio negatiboa aurkitu zen. Aldagai garrantzitsuenen arteko korrelazioak 2. taulan zehaztu dira.

2. taula. HADS azpieskalen eta aldagai biologikoen arteko korrelazioak. ${ }^{*} p<0,05{ }^{* *} p<0,01$

\begin{tabular}{lccccc}
\hline IL-6 & TNF- $\alpha$ & Kortisola & $\begin{array}{c}\text { Antsietatea } \\
\text { (HADS) }\end{array}$ & $\begin{array}{c}\text { Depresioa } \\
\text { (HADS) }\end{array}$ \\
\hline TNF- $\alpha$ & Pearson & $.446^{* *}$ & $-0,140$ & $-.235^{*}$ & $-0,006$ \\
& Pearson & $<, 001$ & 0,208 & 0,036 & 0,961 \\
\hline Kortisola & Pearson & & 0,035 & $-0,155$ & 0,092 \\
& $\mathrm{p}$ & & 0,764 & 0,168 & 0,419 \\
& Antsietatea & Pearson & & $.215^{*}$ & $.226^{*}$ \\
& $\mathrm{p}$ & & & 0,007 & 0,048 \\
\hline
\end{tabular}

HADS eskalan depresioa eta depresio eza agertutako emakumeen neurketa biologikoak alderatzean, depresio-sintomak zituzten emakumeek kortisol-maila altuagoak zituztela aurkitu genuen $(F(1,78)=$ 5.512; $p=0,02$ ). Era berean, depresio-sintoma esanguratsuak zituzten emakumeetan TNF- $\alpha$ maila handiagoak izateko joera nabarmendu zen, esanguratsua izatera iritsi gabe $(F(1,78)=3.304 ; p=$ $0,07)$. Ez zen bi taldeen arteko ezberdintasun esanguratsurik aurkitu IL-6 mailei dagokienez $(F(1,78)=$ .249; $p=0,62$ ) (1. irudia). 
1. irudia. Batez besteko IL-6, TNF- $\alpha$ eta kortisol-kontzentrazioa ( \pm batez bestekoaren errore estandarra, BEE) sintoma depresiboaren arabera. ${ }^{*} p<0,05$.
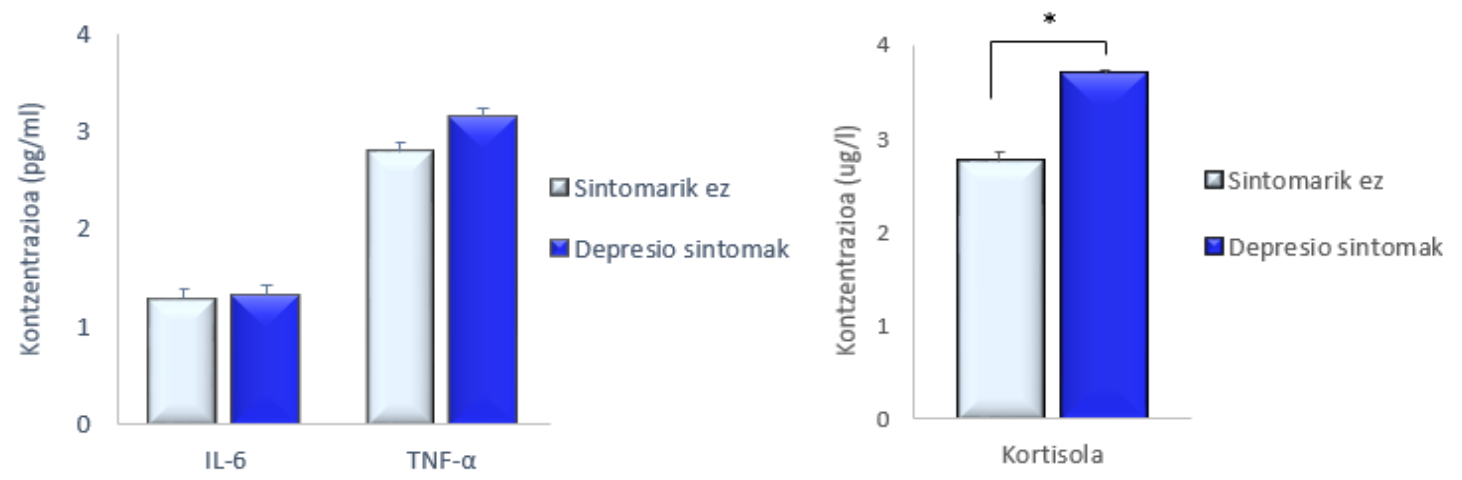

Antsietateari dagokionez, antsietate-maila klinikoak zituzten emakumeek kortisol areagotua erakutsi zuten maila normala zuten emakumeekin erkatuz gero $(F(1,78)=5,546 ; p=0.021)$. TNF- $\alpha(F(1,78)=$ 1,$187 ; p=0,28$ ) eta IL-6 kontzentrazioen harira, ez zen antsietatearen araberako ezberdintasun esanguratsurik aurkitu. Hala ere, azken zitokinaren maila baxuagoak izateko joera erakutsi zuen antsietate-sintomadun taldeak $(F(1,78)=3.250 ; p=0,075)$ (2. irudia).

2. irudia. IL-6, TNF- $\alpha$ eta kortisolaren batez besteko kontzentrazioa ( \pm BEE) antsietatesintomen arabera. ${ }^{*} p<0,05$.
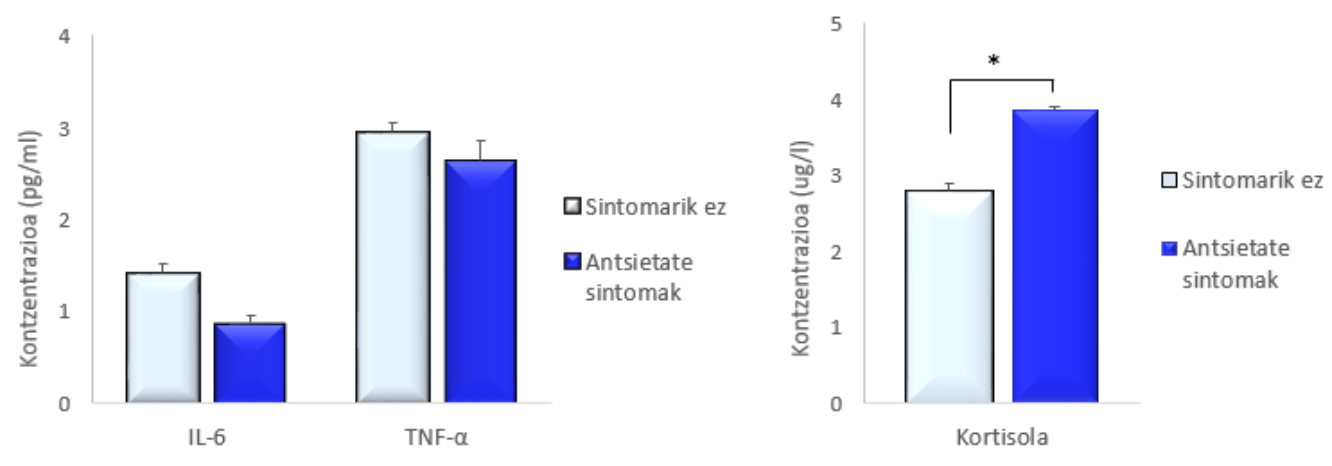

\section{Ondorioak}

Aztertutako laginean depresio-sintomen prebalentzia \% 32,5ekoa izan da, eta antsietatearena \% 31,3koa, bularreko minbizia gainditutako emakumeen inguruko beste ikerketa batzuetan topatutakoak baino portzentaje baxuagoak (\% 40 ko datuak erregistratu dira $(9,10)$ ). Edonola ere, emakumezkoen biztanleria orokorrean aurkitu daitekeena baino prebalentzia handiagoa da, 2018ko Euskadiko Osasun Inkestaren arabera 45-64 urte bitarteko emakumeen \% 17,5ek depresio- eta antsietate-sintomak pairatzen baititu erkidegoan (Gipuzkoara mugatuz gero, $\% 12,8 k)(20)$.

Azpimarratzekoa da, depresioaren hanturaren hipotesia indartuz (15), TNF- $\alpha$ eta kortisol-mailek harreman positiboa erakutsi dutela depresioaren larritasunarekin. Aurreikusi zitekeen moduan, depresioaren eta antsietatearen arteko harreman positiboa agertu da. Biak nahasmendu afektiboak dira, eta bien arteko muga finkatzea zaila izaten da askotan. Gainera, emakumezkoetan bereziki, sintomatologia depresiboa eta antsiosoa batera ager daitezke (21). Bi zitokinen arteko korrelazioa gauza arrunta da, hantura-zitokina ezberdinek jariatze-patroi berberei jarraitzen baitiete. IL-6aren eta antsietatearen arteko korrelazioa ez zen, ordea, esperotakoa, antsietatea estresari -eta hipotesiaren arabera hanturari- lotutako nahasmendua baita.

Bularreko minbizia gainditutako emakumez osatutako gure laginean, depresioa eta antsietatea dutenek kortisol-maila handiagoak dituzte, estres-erantzuna erregulatzeaz arduratzen den HPA 
ardatzaren funtzionamendu egokia eten den seinale, eta emakumeek bizitako egoera gainditu eta egunerokotasunera egokitzeko izan dezaketen zailtasunaren seinale. Izan ere, estres-iturri izan daitezkeen kezka psikosozial garrantzitsuak hauteman dira populazio honetan: ugalkortasunaren, harreman sexualen, lanaren eta bikote eta familiarteko harremanen inguruan batik bat (22). Depresio-sintoma klinikoak zituzten emakumeetan aurkitutako TNF- $\alpha$ maila handiak bat datoz aurretiko beste ikerlan batzuekin $(16,17)$, baita depresioaren hanturaren hipotesiarekin ere (15). Aipatzekoa da, hantura-zitokina eta kortisol-maila handiak hainbat osasun-arazo agertzeko aukera handiagoa izatearekin lotu direla; gaixotasun kardiobaskularrak, osteoporosia, eta artritisa esaterako (23). Baliteke, beraz, kortisola eta TNF$\alpha$ zitokina subjektu zaurgarriak identifikatu eta jarraipen eta prebentzio esku-hartzeak egiteko irizpide baliagarriak izatea. Hori gutxi balitz bezala, hantura kronikoa eta HPA ardatzaren desregulazioa tumore-zelulen proliferazioarekin, minbizia berragertzearekin eta hilkortasuntasa handiagoarekin lotu da (21). Edonola ere, aurrera begira, interesgarria litzateke hanturazitokinak ez ezik, zitokina antiinflamatorioak ere neurtzea. Izan ere, azken ikerketen arabera, zitokina pro- eta anti-inflamatorioen arteko orekak norbanakoaren hantura-egoeraren informazio zehatzagoa ematen digu, bien arteko desoreka baten edo bestearen maila altuak baino arriskutsuagoa delarik $(24,25)$. Antsietatea zuten parte-hartzaileetan aurkitutako IL-6 maila baxuen kasuan ere, baliteke zitokina anti-inflamatorioak ere kontzentrazio txikian izatea, eta horrela IL-6aren eragina orekatua edo negatiboa izatea.

Ikerketa honen mugei dagokienez, kontuan izatekoa da laginaren tamaina xumea eta haren homogeneotasuna. Ikerketa hau beste xede-biztanleria batzuetan errepikatu beharko litzateke emaitzak orokortu ahal izateko. Bestetik, parte-hartzea borondatezkoa zenez, baliteke boluntariotzarako joera profil psikologiko edo emozional konkretuekin lotuta egotea, eta hortaz, gure laginak errealitate orokorra ez islatzea.

Minbizia gainditutako pertsonen egoera emozionalaren azpian dautzan faktore psikobiologikoen ezagutza sakonagoak zainketa integratu eta pertsonalagoak eskaintzea ahalbidetuko liguke, bizi-kalitatea hobetu eta osasun-arazoak ekidite aldera.

\section{Etorkizunerako planteatzen den norabidea}

Ikerketa-lerro berean jaso ditugun beste datu batzuen arabera, bularreko minbizia gainditutako emakumeengan, TNF- $\alpha$ maila altuak eta babes sozial eskasa aldi berean ematen direnean, distres psikologikoa handiagoa da (26). Emaitza horiek, lan honetan aurkeztutakoekin batera, zera adierazten dute: TNF- $\alpha$ eta kortisol-maila altuak nahasmendu afektiboak izateko arrisku handiagoarekin lotzen badira ere, babes sozialak eta erronkari aurre egiteko baliabideak izateak antsietate- edo depresio-sintomen agerpena modula dezaketela.

Hori dela eta, Elkar Laguntza izeneko proiektua jarri dugu abian Onkologikoa Fundazioan. Bertan, minbizia diagnostikatu berri zaien pazienteei antzeko ezaugarriak dituen kide boluntario bat esleitzen zaie, minbizia gainditu zuena eta erabat osatuta dagoena, jarraipen-hitzorduen bidez babes soziala eskaintzeko, harik eta diagnostikatu diren paziente berriek prozesu osoa amaitzen duten arte. Urteetako jarraipena eginda aztertu ahal izango dugu proiektu honek pazienteen osasun-emaitzetan eta aldagai biologiko eta psikologikoetan onurarik dakarren, baita minbizia gainditu osteko bizikalitatea hobetzen lagun dezakeen ere.

\section{Eskerrak eta oharrak}

Ikerketa hau Eusko Jaurlaritzaren talde kontsolidatuentzako IT-757-13 laguntzari esker egin da.

\section{Erreferentzia bibliografikoak}

1. Allemani C, Weir HK, Carreira H, Harewood R, Spika D, Wang X-S, et al. Global surveillance of cancer survival 1995-2009: analysis of individual data for 25676887 patients from 279 population-based registries in 67 countries (CONCORD-2). Lancet. 2015;385(9972):977-1010. 
2. Global Cancer Observatory [Internet]. International agency for research on cancer: World Health Organization. 2018 [Kontsulta: 2019-09-22]. Eskuragarri:

https://data.worldbank.org/indicator/NY.GDP.PCAP.CD

3. Evans J, Atherton I, Dibben C, Hubbard G. The health and well-being of people with a previous diagnosis of cancer : a record-linkage study in Scotland. J Public Heal Epidemiol. 2011;3(10):429-732.

4. Phillips-Salimi CR, Andrykowski MA. Physical and mental health status of female adolescent/young adult survivors of breast and gynecological cancer: a national, populationbased, case-control study. Support Care Cancer. 2013; 21(6):1597-604.

5. Romito F, Cormio C, Giotta F, Colucci G, Mattioli V. Quality of life, fatigue and depression in Italian long-term breast cancer survivors. Support Care Cancer. 2012; 20(11):2941-48.

6. Holland J, Deshields TL, Andersen B, Braun I, Breitbart WS, Brewer BW, Buchmann L, Collins M, Corbett C, Donovan KA, Fleishman S, Garcia S, Greenberg DB, Handzo GF, Hoofring L, Lally R, Martin S, McGuffey L, Mitchell W, Morrison LJ, Palesh O, Parnes F, Pazar JP, Riba MB, Salman J, Scrivani R, Shannon-Dudley MM, Valentine AD, Weinstein E. NCCN clinical practice guidelines in oncology: distress management. 2. bertsioa [Internet]. [Plymouth Meeting, PA]: National Comprehensive Cancer Network; 2018 [Kontsulta: 2019-06-24]. 92 or. Eskuragarri: https://oncolife.com.ua/doc/nccn/Distress_Management.pdf

7. Adler N, Page A, Page, Institute of Medicine (IOM) (ed.). Cancer care for the whole patient: meeting psychosocial health needs [Internet]. Washington, DC: The National Academies Press; 2008 [Kontsulta: 2019-06-24]. 455 or. Eskuragarri: https://www.ncbi.nlm.nih.gov/books/NBK4015/pdf/Bookshelf_NBK4015.pdf

8. Stanton AL, Bower JE. Psychological adjustment in breast cancer survivors. Adv Exp Med Biol. 2015;862: 231-42.

9. Stanton AL. Psychosocial concerns and interventions for cancer survivors. J Clin Oncol. 2006; 24(32):5132-7.

10. Burgess C, Cornelius V, Love S, Graham J, Richards M, Ramirez A. Depression and anxiety in women with early breast cancer: five year observational cohort study. BMJ. 2005; 330(7493):702.

11. Smith HR. Depression in cancer patients: Pathogenesis, implications and treatment (review). Oncol Lett. 2015;9(4):1509-14.

12. Furtado M, Katzman MA. Examining the role of neuroinflammation in major depression. Psychiatry Res. 2015;229(1-2):27-36.

13. Furtado M, Katzman MA. Neuroinflammatory pathways in anxiety, posttraumatic stress, and obsessive compulsive disorders. Psychiatry Res. 2015;229(1-2):37-48.

14. Zachariae R. Psychoneuroimmunology: a bio-psycho-social approach to health and disease. Scand J Psychol. 2009;50(6):645-51.

15. Raison CL, Capuron L, Miller AH. Cytokines sing the blues: inflammation and the pathogenesis of depression. Trends Immunol. 27(1):24-31.

16. Kesler S, Janelsins M, Koovakkattu D, Palesh O, Mustian K, Morrow G, Dhabhar FS. Reduced hippocampal volume and verbal memory performance associated with interleukin- 6 and tumor necrosis factor-alpha levels in chemotherapy-treated breast cancer survivors. Brain Behav Immun. 2013. 30 Suppl: S109-16.

17. Lengacher CA, Reich RR, Paterson CL, Shelton M, Shivers S, Ramesar S, Pleasant ML, Budhrani-Shani P, Groer M, Post-White J, Johnson-Mallard V, Kane B, Cousin L, Moscoso MS, Romershausen TA, Park JY. A large randomized trial: effects of mindfulness-based stress reduction (MBSR) for breast cancer (BC) survivors on salivary cortisol and IL-6. Biol Res Nurs. $2019 ; 21(1): 39-49$.

18. Zigmond AS, Snaith RP. The hospital anxiety and depression scale. Acta Psychiatr Scand. 1983;67(6):361-70.

19. López S, Pastor-Mira MA, Terol Cantero M del C. Ansiedad y depresión. Validación de la Escala HAD en pacientes oncológicos. Rev Psicol la salud. 2000;12:127.

20. ESCAV: Encuesta de Salud del País Vasco 2018 [Internet]. Eusko Jaurlaritza [Kontsulta: 201911-29]. Eskuragarri: https://www.euskadi.eus. 
21. Keers R, Aitchison KJ. Gender differences in antidepressant drug response. Int Rev Psychiatry. 2010;22(5):485-500.

22. Crowley SA, Foley SM, Wittmann D, Jagielski CH, Dunn RL, Clark PM, Griggs JJ, Peterson C, Leonard M, An LC, Wei JT, Montie JE, Janz NK. Sexual Health concerns among cancer survivors: testing a novel information-need measure among breast and prostate cancer patients. J Cancer Educ. 2016; 31(3):588-94.

23. Currier MB, Nemeroff CB. Depression as a risk factor for cancer: from pathophysiological advances to treatment implications. Annu Rev Med. 2014;65:203-21.

24. Capuron L, Miller AH. Immune system to brain signaling: neuropsychopharmacological implications. Pharmacol Ther. 2011; 130(2):226-38.

25. Labaka A, Gómez-Lázaro E, Vegas O, Pérez-Tejada J, Arregi A, Garmendia L. Reduced hippocampal IL-10 expression, altered monoaminergic activity and anxiety and depressivelike behavior in female mice subjected to chronic social instability stress. Behav Brain Res. 2017;335: 8-18.

26. Perez-Tejada J, Labaka A, Pascual-Sagastizabal E, Garmendia L, Iruretagoyena A, Arregi A. Predictors of psychological distress in breast cancer survivors: A biopsychosocial approach. Eur J Cancer Care. 2019;28(6): e13166. 